\title{
Contact Lens-Related Infectious Keratitis: Review of 29 Cases
}

\author{
Sana Khochtali, Nadia Daldoul, Sourour Zina, Imen Ksiaa, Sonia Zaouali, \\ Béchir Jelliti, Moncef Khairallah
}

Department of Ophthalmology, Fattouma Bourguiba University Hospital, Monastir, Tunisia

Email: amira.krir@outlook.com

How to cite this paper: Khochtali, S., Daldoul, N., Zina, S., Ksiaa, I., Zaouali, S., Jelliti, B. and Khairallah, M. (2017) Contact Lens-Related Infectious Keratitis: Review of 29 Cases. Open Access Library Journal, 4: e3815.

https://doi.org/10.4236/oalib.1103815

Received: July 11, 2017

Accepted: October 9, 2017

Published: October 12, 2017

Copyright ( 2017 by authors and Open Access Library Inc.

This work is licensed under the Creative Commons Attribution International License (CC BY 4.0).

http://creativecommons.org/licenses/by/4.0/

\begin{abstract}
Aim: To describe the epidemiological, clinical, microbiological and therapeutic features of corneal abscesses related to Contact Lens (CL) wear. Patients and Methods: Retrospective review of 29 patients (29 eyes) with infectious keratitis associated with contact lens wearing was conducted at Ophthalmology Department Fattouma Bourguiba University Hospital of Monastir, Tunisia between January 2006 and June 2016. All patients underwent detailed ophthalmological examination. Slit lamp examination and corneal culture were performed on all patients. The Contact Lens and Contact Lens cases were also analyzed if available. The mean follow-up period was 88 days (range: 30 - 360 days). Results: The mean age of our patients was 27 year old. Twenty-three patients (97.3\%) were females and 6 patients (20.7\%) were males. Twenty-seven patients (93.1\%) were soft contact lens users. The mean initial Visual Acuity (VA) was 20/1000. Stromal infiltrates were associated with ulcers in all cases, and were located in central cornea in 21 cases (72.4\%). Hypopyon was noted in 10 cases (34.5\%). Microbial cultures were positive in 18 patients (72.4\%). Pseudomonas aeruginosa was isolated in $41.4 \%$ of cases. Amoebic cysts were found in 5 cases (17.3\%). Fusarium was isolated in one eye (3.5\%). Antimicrobial treatment was based on the suspected or isolated causative agent. Final VA was 20/125. Conclusion: Corneal abscesses are a rare but serious complication of CL wear. Educating CL users, early diagnosis and appropriate management are important elements so as to reduce ocular morbidity.
\end{abstract}

\section{Subject Areas \\ Ophthalmology}

\section{Keywords}

Contact Lens, Infectious Keratitis, Hypopyon, Stromal Infiltrates 


\section{Introduction}

Corneal abscess is a rare and severe complication of Contact Lens wear. It is a diagnostic and therapeutic emergency as it is potentially blinding. The increasing use of contact lens (CL) in the world has increased the prevalence of these abscesses. The positive diagnosis of contact lens-related infectious keratitis is clinical. The diagnosis of the causative germ may be oriented by clinical presentation, but it is only certain in case of microbiological evidence from corneal sampling [1] [2] [3]. The treatment is mainly based on adapted anti-infectious eye drops. We conducted a retrospective study of 29 eyes of 29 CL-wearing patients hospitalized in the Ophthalmology Department of Fattouma Bourguiba University Hospital of Monastir between January 2006 and June 2016. The aim of this work were to study the epidemiological and clinical signs of corneal abscesses related to the use of CL, to identify the microbiological particularities and to determine the therapeutic modalities and their results.

\section{Patients and Methods}

This is a retrospective study of 29 patients with a history of wearing contact lenses, are presented with corneal abscesses to Monastir's Department of ophthalmology between January 2006 and June 2016. The inclusion criteria of our study were the wear of CL in the days before the onset of symptoms and a follow-up period of more than 1 month in the medical files. Patients with therapeutic use of CL (therapeutic lens), or having a history of keratoplasty or cataract surgery, or Herpetic keratitis, or a general comorbidity that may have major repercussion on the ocular surface (e.g. polyarthritis Rheumatoid or Sjögren's syndrome) were excluded.

All patients underwent an ophthalmological examination including questioning about their medical records, measurement of the best corrected Visual Acuity using log MAR, eyelid examination (research of blepharitis and a test of lacrymal ducts permeability), study of corneal sensitivity (with a simple cotton contact sensitivity test) and a slit lamp corneal examination without and with fluorescein test, We specify the characteristics of the abscess (size, localization, number, shape, aspect of the edges, existence of stromal infiltration)

Anterior chamber and lens examination followed by vitreous and ocular fundus checking was performed when the transparency of the cornea made it possible.

All patients underwent corneal scraping samples for microbial analysis (Scraping of the ulcer and the edges of the ulcer by scalpel blade and its spreading on three slides, specific Gram, Giemsa and PAS staining with culture in specific media)

Contact lenses and contact lenses cases were analysed if available. Presumptive anti-infectious treatment, according to the suspected germ (Fortified antibacterial eye drops (Vancomycin, Gentamycin, Ceftazidim) was administered at the time of admission and adapted according to the microbiological findings and 
evolution. During their hospitalization, patients were examined twice daily during the first days of their hospitalization and then daily until they were discharged.

Statistic analysis was made by MS Excel ${ }^{\oplus}$, SPSS $^{\oplus} 20$ and Statview ${ }^{\circledR} 5$ software. The choice of the appropriate test was made according to the type of variable, the number of modalities in a variable and the sample size: (Pearson correlation coefficient, Universal correlation test $\mathrm{Z}, \mathrm{Chi}^{2}$ contingency test, Anova test, Fischer PLSD test, Student's t test)

\section{Results}

The mean age of our patients was 27 years old with a female predominance (sex ratio of 0.26$)$. The vast majority of the contact lenses: 28 cases (97.6\%) were soft lenses. In 8 of cases (27.6\%): poor contact lenses hygiene was found during interrogation. This was mainly the washing of CL with tap water (10.3\% of cases) and prolonged wearing for up to 3 consecutive days (13.8\% of cases). All patients had ocular pain and redness (100\%). The period of presentation to our Department was 13 days (range: 1 to 120 days). The mean initial Visual Acuity (VA) was $1 / 50$ (ranging between positive light perception (PL+) and 6/10), this latter was less than $1 / 10$ in $89.7 \%$ of the cases. The corneal abscess was unilateral in all our patients, unifocal in 24 cases (86.2\%) and centrally located in 20 cases (69\%). Its mean diameter was $3.9 \mathrm{~mm}$ (range $1-10 \mathrm{~mm}$ ). Deep stromal infiltration ( $>50 \%)$ was observed in 23 cases $(79.3 \%)$ as shown in Figure 1(a). A positive fluorescein corneal ulcer was found in all cases as demonstrated in Figure 1(b). An inflammatory reaction of the anterior chamber was found in 16 cases (55.2\%), with hypopyon in 10 cases (34.4\%). All our patients underwent corneal scraping. A microbiological analysis was performed on contact lenses in 13 cases (44.8\%) and on the contact lens cases in 10 cases (34.5\%). The samples were positive in 21 patients $(72.4 \%)$. The cause of keratitis was bacterial in 18 cases (62.1\%) as demonstrated in Figure 1, amoebic in 7 cases (24.1\%) as described in Figure 2 and Figure 3, fungal in 4 cases (13.8\%) and polymicrobial in 8 cases (27.6\%) as represented in Figure 4. The isolated germs are summarized in Table 1.

Table 1. Distribution of the germs found in our series.

\begin{tabular}{ccc}
\hline Germs & Positive sample number & Positive sample percentage \\
\hline Pseudomonas aeruginosa & 12 & $57.1 \%$ \\
Coagulase-negative staphylococcus & 5 & $23.8 \%$ \\
Klebsiella pneumoniae & 3 & $14.3 \%$ \\
Klebsiella oxytoca & 1 & $4.8 \%$ \\
Citrobacter & 1 & $4.8 \%$ \\
Staphylococcus aureus & 1 & $4.8 \%$ \\
Serratia marcescens & 1 & $4.8 \%$ \\
Amoebae (cysts) & 5 & $23.8 \%$ \\
Fusarium & 1 & $4.8 \%$ \\
\hline
\end{tabular}




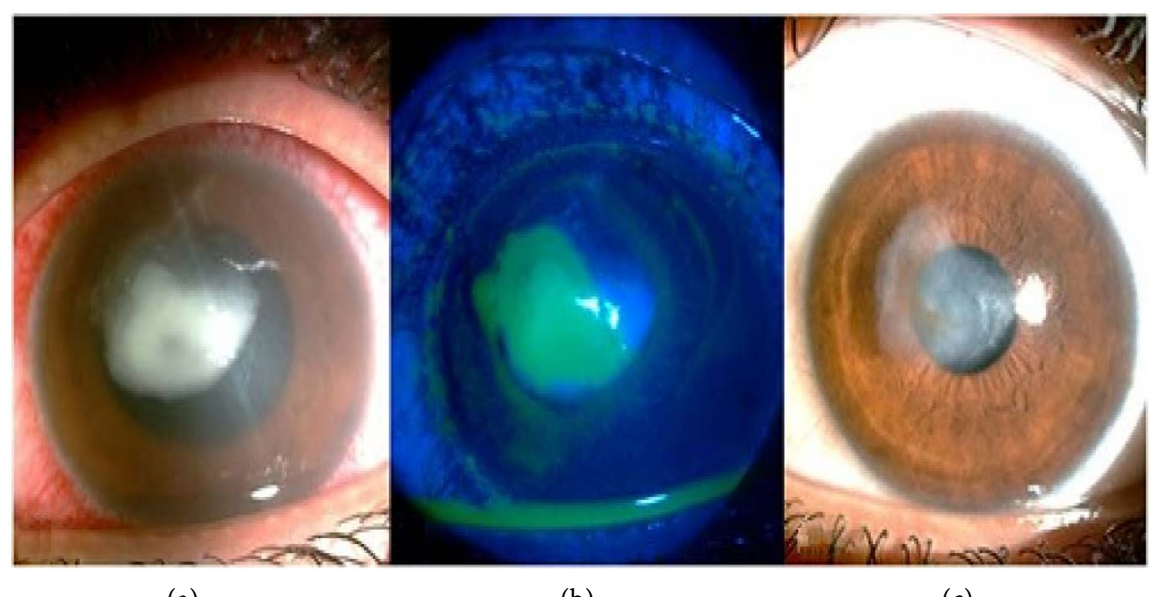

(a)

(b)

(c)

Figure 1. A 28-year-old patient: Anterior segment photography showing a central corneal abscess of $5 \mathrm{~mm}$ diameter with overlying sticky secretions, deep stromal infiltration (a) and overlying ulceration (b); the sample has objectified pseudomonas aeruginosa; (c) evolution after 2 months, objectifying a central scar (final VA corrected to $2 / 10$ ).

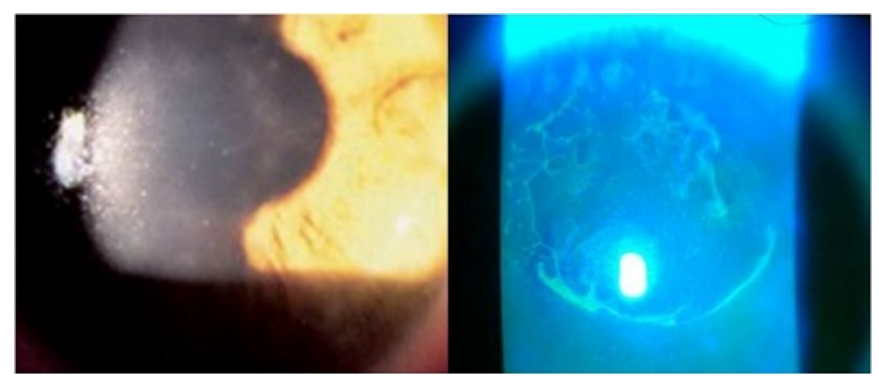

Figure 2. A 36-year-old patient: Anterior segment photography showing multiple epithelial and subepithelial infiltrates, with a pseudo-dendritic ulceration. The corneal sampling has objectified amoeba cysts.

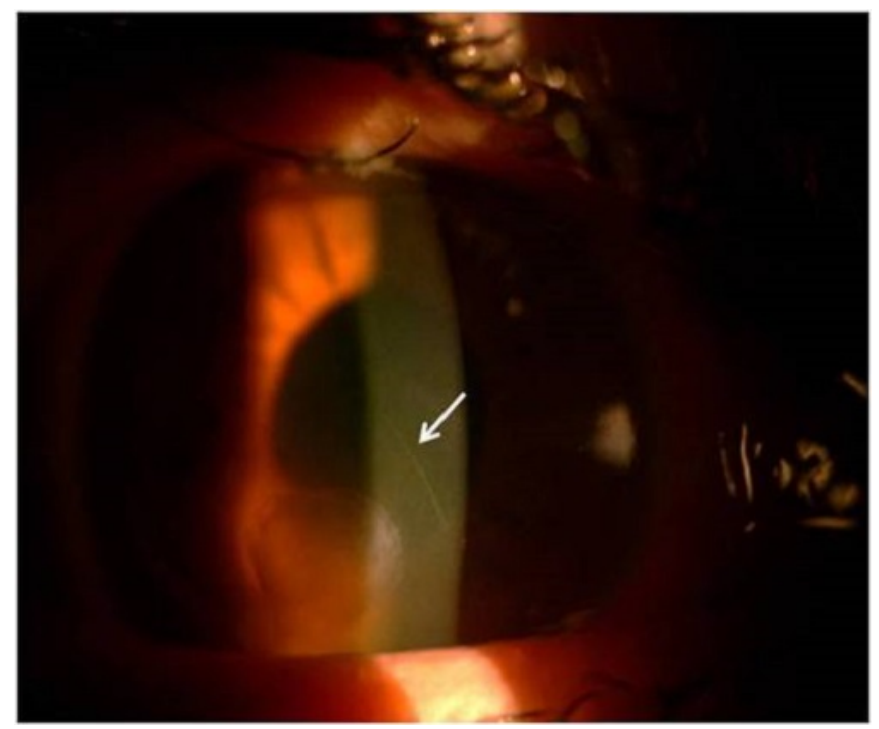

Figure 3. A 26-year-old patient: Photograph of the anterior segment showing translucent corneal infiltration of $2.5 \mathrm{~mm}$ in diameter with a radial keratoneuritis (arrow). The diagnosis of amoebic keratitis was presumed. 


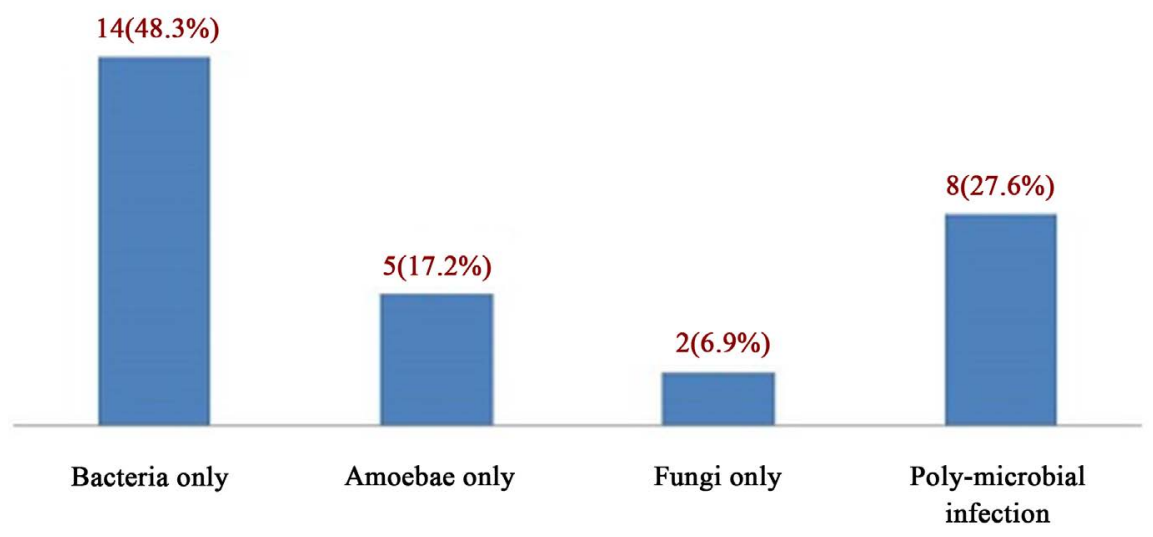

Figure 4. Distribution of germs causing infectious keratitis in our patients (proven or suspected causative organism).

The combination of Ceftazidime-Vancomycin and Ceftazidime-Gentamicin fortified antibiotics were performed in 17 (58.6\%) and 5 cases $(17.2 \%)$, respectively. Treatment with fortified antibiotics was relayed in cases of bacterial keratitis by conventional eye drops (an Aminoglycoside associated to Fluoroquinolone in 16 cases (55.2\%)).

The treatment of amoebic keratitis was based on Hexamidine associated with PolyHexaMéthylène Biguanide (PHMB) in 1 case (3.4\%), Picloxydine in 3 cases (10.3\%) and Neomycin in 3 cases (10.3\%).

General Fluconazole was administered to 2 patients (6.9\%). The treatment of fungal keratitis involved Amphotericin B eye drops in 1 case, Ketoconazole in 1 case and Voriconazole in 2 cases. General fluconazole was administered in 3 cases $(10.3 \%)$ with severe fungal infection.

An anti-inflammatory treatment based on topical or general corticosteroids was administered in 5 cases (17.2\%) of bacterial keratitis and in 6 cases (20.7\%) of polymicrobial keratitis, on an average of 20 days after the beginning of the anti-infectious treatment. One patient underwent penetrating keratoplasty, one year after the infectious episode.

The mean follow-up period was 2 months and half (range: 1 month - 1 year). The mean final VA was 0.16 (range: $1 / 200$ to $8 / 10$ ). The final VA was $\leq 1 / 10$ in $47.8 \%$, and it was $\geq 5 / 10$ in $21.7 \%$ of cases. The difference between the initial VA and the final VA was significant $(p<0.001)$. A poor final VA was significantly correlated with a poor initial VA $(p=0.037)$ : the difference between the initial $\mathrm{AV}$ and the final AV was significant with $p<10^{-3}$, and with the presence of hypopyon $(p=0.03)$. All patients showed a cicatricial corneal opacity of varying degrees. The scar was central in 20 cases (69\%) and para-central in 9 cases $(31 \%)$ as illustrated in Figure 1(c).

\section{Discussion}

In our study, the initial average of visual acuity (VA) was $1 / 50$, hypopion was 
found in $34.5 \%$ of cases. The samples were positive in 21 patients $(72.4 \%)$. The cause of keratitis was bacterial in 18 cases (62.1\%), amoebic in 7 cases $(24.1 \%)$, fungal in 4 cases $(13.8 \%)$ and polymicrobial in 8 cases $(27.6 \%)$. The most frequently isolated germ was pseudomonas aeruginosa (41.4\%). The final VA was $\leq$ $1 / 10$ in $47.8 \%$ of cases with an average follow-up of 88 days.

The average age of patients was 27 years (range: 19 - 48). Previous studies also found a young average age of patients with corneal abscess on contact lenses between 22 and 35 years [1] [3] [4] [5].

The female predominance noted in our series is often found in the literature [6]. In our series, the vast majority of contact lenses (28 cases: $97.6 \%$ ) were soft lenses, in 8 cases $(27.6 \%)$ : poor contact lenses hygiene was found during the interrogation. This was mainly the washing of contact lens with tap water $(10.3 \%$ of cases) and prolonged wear for up to 3 consecutive days (13.8\% of cases). These findings were consistent with the literature. Indeed, the soft nature of CL and the night wear are considered the main risk factors for infectious complications [7] [8] [9] [10]. In addition, non-compliance to maintenance rules observed in $40 \%$ to $60 \%$ of contact lens users is directly involved in the development of corneal abscesses [11] [12]. The period of presentation to our Department was 13 days (range: 1 to 120 days). This period was less than or equal to 7 days in $69 \%$ of cases. In the literature, the average consultation period was 4.6 days in the Netherlands as discussed by Hoddenbach [1], 2 days in France as cited by Bourcier [13] and 5 days in a Moroccan study realized by Benhmidoune and et al. [3]. The corneal abscess in our series was unilateral in all cases (100\%). Bilateralism is rarely reported in studies of literature [1] [3] [4] [5].

The mean initial VA was 1/50 (extremes: positive light perception (PL+) to $6 / 10$ ), VA was less than $1 / 10$ in $89.7 \%$ of the cases. Our results are close to those reported in the majority of series [1] [3]. The corneal abscess was unifocal in 24 cases $(86.2 \%)$ and centrally located in 20 cases (69\%) with an average diameter of $3.9 \mathrm{~mm}$ (range: 1 to $10 \mathrm{~mm}$ ). Our results are consistent with those of the majority of published series [1] [2] [3]. In our series, a stromal infiltration of more than $50 \%$ was noted in $79 \%$ of the eyes. In a recent Moroccan study [3], deep stromal involvement was noted in $52.9 \%$. The degree of stromal infiltration is a sign of severity of the corneal abscess. Hypopyon is also often considered as a sign of severity of infectious keratitis as reported by Keay [5]. In our study, an inflammatory reaction of the anterior chamber with hypopyon was found in 10 eyes (34.4\%). In a Moroccan study and a Dutch study, hypopyon was found in $47.1 \%$ and $58.7 \%$ of the patients respectively [1] [3], which is close to the rate observed in our work.

Corneal specimens are essential to identify the causative pathogen as demonstrated by Garg and et al. [14]. In our study, samples were positive in 21 patients (72.4\%), which is a fairly high percentage compared to studies conducted in the United States [15], Morocco [3] and Sweden [16] where positivity was between $43 \%$ and $59 \%$. Auto-medication of patients before hospitalization and the lack of coordination with the laboratory may decrease the chance of isolating a germ as 
cited by Benhmidoune [3]. Due to their low specificity, contact lenses or contact lens cases culture will be mainly useful in the etiological diagnosis when corneal scratch culture returns negative as demonstrated elsewhere [17]. The first etiology of infectious keratitis in contact lenses users worldwide was bacterial (range $80 \%-94.2 \%)$, followed by amoebic infection (1.5\% - 17.7\%), followed by fungal infection (1\% to $4.3 \%)$ as described in these reports [3] [10] [13] [18]. These results are close to those found in our study with a lower frequency for bacterial keratitis (62.1\%) versus a higher frequency for amoebic (17.2\%) and fungal keratitis $(6.9 \%)$. Polymicrobial keratitis is rarely described in the series of corneal abscesses [3]. The level of polymicrobial keratitis was $27.6 \%$ in our series.

Bacterial keratitis accounts for up to $90 \%$ of infectious keratitis $(62.1 \%$ in our series). Gram negative bacteria with Pseudomonas at the top were the most frequently found germs in corneal abscesses followed by Staphylococcus [11] [12] as well as in our series.

The final VA, in case of corneal abscess related to CL wear, may be less than $1 / 10$ in nearly half of cases as reported by Hoddenbach and et al. [1]. In our series, the final VA average was 0.16 (extremes: $1 / 200$ to $8 / 10$ ). Final VA was $\leq 1 / 10$ in $47.8 \%$ of cases, and was $\geq 5 / 10$ in $21.7 \%$ of cases. The difference between the initial VA and the final VA was significant $(p<0.001)$. The factors of poor visual prognosis found in our series were essentially a poor initial VA and the presence of hypopyon as reported elsewhere [1] [3] [19].

\section{Conclusions}

In conclusion, corneal abscesses represent serious complication of CL wear. They affect young patients, mainly females. This infectious keratitis is most often bacterial. The amoebic cause comes in second position, followed by the fungal origin. The etiological diagnosis is suspected based on clinical examination data, and is proved by corneal specimens. Treatment is initially presumptive, then adapted according to microbiological and evolutionary findings.

Despite adequate management, the visual prognosis may be reserved. Further efforts should be made for an earlier diagnosis and more specifically measures in preventing this potentially blinding complication of the contact lenses wear.

\section{Conflict of Interest}

All authors declares no conflict of interest.

\section{References}

[1] Hoddenbach, J.G., Boekhoorn, S.S., Wubbels, R., Vreugdenhil, W., Van Rooij, J. and Geerards, A.J.M. (2014) Clinical Presentation and Morbidity of Contact Lens-Associated Microbial Keratitis: A Retrospective Study. Graefe's Archive for Clinical and Experimental Ophthalmology, 252, 299-306.

[2] Verhelst, D., Koppen, C., Van Looveren, J., Meheus, A. and Tassignon, M.-J. (2006) the Belgian Keratitis Study Group. Contact Lens-Related Corneal Ulcersrequiring Hospitalization: A 7-Year Retrospective Study in Belgium. Acta Ophthalmologica 
Scandinavica, 84, 522-526. https://doi.org/10.1111/j.1600-0420.2006.00681.x

[3] Benhmidoune, L., Bensemlali, A., Bouazza, M., Karami, R., El Mansouri, H., ElBelhadji, M., et al. (2013) Contact Lens Related Corneal Ulcers: Clinical, Microbiological and Therapeutic Features. Journal Francais D' Ophtalmologie, 36, 594-599. https://doi.org/10.1016/j.jfo.2012.06.026

[4] Goh, P.P., Shamala, R., Chandamalar, S. and Tai, X.Y. (2010) National Eye Database Study Group. Contact Lens-Related Corneal Ulcer: A Two-Year Review. Medical Journal of Malaysia, 65, 120-123.

[5] Keay, L., Edwards, K. and Stapleton, F. (2009) Signs, Symptoms, and Comorbidities Incontact Lens-Related Microbial Keratitis. Optometry and Vision Science, 86, 803-809. https://doi.org/10.1097/OPX.0b013e3181ae1b69

[6] Wagner, H., Richdale, K., Mitchell, G.L., Lam, D.Y., Jansen, M.E., Kinoshita, B.T., et al. (2014) Age, Behavior, Environment, and Health Factors in the Soft Contact Lens Risk Survey. Optometry and Vision Science, 91, 252-261.

[7] Cheng, K.H., Leung, S.L., Hoekman, H.W., Beekhuis, W.H., Mulder, P.G., Geerards, A.J., et al. (1999) Incidence of Contact-Lens-Associated Microbial Keratitis and Itsrelated Morbidity. Lancet, 354, 181-185. https://doi.org/10.1016/S0140-6736(98)09385-4

[8] Stapleton, F., Keay, L., Edwards, K., Naduvilath, T., Dart, J.K.G., Brian, G., et al. (2008) The Incidence of Contact Lens-Related Microbial Keratitis in Australia. Ophthalmology, 115, 1655-1662. https://doi.org/10.1016/j.ophtha.2008.04.002

[9] Dart, J.K.G., Radford, C.F., Minassian, D., Verma, S. and Stapleton, F. (2008) Risk Factors Formicrobial Keratitis with Contemporary Contact Lenses: A CaseControlstudy. Ophthalmology, 115, 1647-54, 1654.e1-3.

[10] Keay, L., Edwards, K., Naduvilath, T., Taylor, H.R., Snibson, G.R., Forde, K., et al. (2006) Microbial Keratitis. Ophthalmology, 113, 109-116. https://doi.org/10.1016/j.ophtha.2005.08.013

[11] Yeung, K.K., Forister, J.F.Y., Forister, E.F., Chung, M.Y., Han, S. and Weissman, B.A. (2010) Compliance with Soft Contact Lens Replacement Schedules and Associatedcontact Lens-Related Ocular Complications: The UCLA Contact Lens Study. Optometry, 81, 598-607.

[12] Morgan, P.B., Efron, N., Toshida, H. and Nichols, J.J. (2011) An International Analysis of Contact Lens Compliance. Contact Lens Anterior Eye, 34, 223-228.

[13] Bourcier, T., Thomas, F., Borderie, V., Chaumeil, C. and Laroche, L. (2003) Bacterial Keratitis: Predisposing Factors, Clinical and Microbiological Review of 300 Cases. British Journal of Ophthalmology, 87, 834-838. https://doi.org/10.1136/bjo.87.7.834

[14] Garg, P. (2010) Diagnosis of Microbial Keratitis. British Journal of Ophthalmology, 94, 961-962. https://doi.org/10.1136/bjo.2010.182550

[15] Alexandrakis, G., Alfonso, E.C. and Miller, D. (2000) Shifting Trends in Bacterial Keratitisin South Florida and Emerging Resistance to Fluoroquinolones. Ophthalmology, 107, 1497-1502.

[16] Nilsson, S.E. and Montan, P.G. (1994) The Hospitalized Cases of Contact Lens Inducedkeratitis in Sweden and Their Relation to Lens Type and Wear Schedule: Results of a Three-Year Retrospective Study. The CLAO Journal, 20, 97-101.

[17] Szczotka-Flynn, L.B., Pearlman, E. and Ghannoum, M. (2010) Microbial Contamination of Contact Lenses, Lens Care Solutions, and Their Accessories: A Literature Review. Eye Contact Lens, 36, 116-129. https://doi.org/10.1097/ICL.0b013e3181d20cae 
[18] Ancele, E., Lequeux, L., Fournié, P., Chapotot, E., Douat, J. and Arné, J.-L. (2009) Severe Bacterial Keratitis. A Clinical, Epidemiologic, and Microbiologic Study. Journal Francais D' Ophtalmologie, 32, 558-565.

[19] Perol, J., Gaujoux, T., Laroche, L. and Borderie, V.M. (2009) Infectious Keratitis in Contact Lens Wearers: Analysis of Risk Factor, Etiologic Agents and Evolution after Treatment. Journal Francais D' Ophtalmologie, 32, 1S159.

Submit or recommend next manuscript to OALib Journal and we will provide best service for you:

- Publication frequency: Monthly

- 9 subject areas of science, technology and medicine

- Fair and rigorous peer-review system

- Fast publication process

- Article promotion in various social networking sites (LinkedIn, Facebook, Twitter, etc.)

- Maximum dissemination of your research work

Submit Your Paper Online: Click Here to Submit

Or Contact service@oalib.com 